\title{
Facilitation and Delayed Release at Single Frog Neuromuscular Junctions
}

\author{
I. S. Cohen and W. Van der Kloot
}

Department of Physiology and Biophysics, Health Sciences Center, SUNY, Stony Brook, New York 11794

\begin{abstract}
Facilitation and delayed spontaneous release were recorded from neuromuscular junctions at 2 temperatures. In some experiments, $\mathrm{Sr}^{2+}$ substituted for $\mathrm{Ca}^{2+}$. We measured the ratio of delayed release to resting spontaneous release $(D)$, and the ratio of the second end-plate potential amplitude to the first (F). An extension of the model of Barton et al. (1983) relating $\mathrm{Ca}^{2+}$ to evoked and spontaneous release is presented. If residual $\mathrm{Ca}^{2+}$ accounts for facilitation and delayed release, then $D$ must be greater than $F$. In all of our experiments, $D$ was greater than F. We conclude that residual $\mathrm{Ca}^{2+}$ is sufficient to account for facilitation and delayed release at the frog neuromuscular junction. However, $D$ falls abruptly at a time when $F$ is almost unaltered, which raises serious difficulties in accepting the residual calcium hypothesis.
\end{abstract}

Facilitation occurs when a synapse releases more transmitter in response to a second stimulus than it did following the first stimulus. A variety of explanations have been proposed for facilitation, including changes in action potential shape (Baldo et al., 1983; Barton and Cohen, 1982; Charlton and Bittner, 1978; Lloyd, 1949; Mallart and Martin, 1967) and increases in calcium conductance (Hoshi et al., 1984; Stinnakre and Tauc, 1973). The "residual calcium" hypothesis (Katz and Miledi, 1968 ) suggests that after a stimulus it might take substantial time for the calcium concentration in the terminal to fall to the original baseline level. As long as the calcium concentration remains elevated, a second stimulus should increase cytosolic calcium levels above those obtained following the first stimulus and so increase phasic release.

The transitory increase in the spontaneous quantal release rate that follows evoked release is called delayed or late release (del Castillo and Katz, 1954; Erulkar and Rahamimoff, 1978; Hurlbut et al., 1971; Liley, 1956; Miledi and Thies, 1971; Rahamimoff and Yaari, 1973). Delayed release can also be explained by residual calcium, because as long as the cytosolic calcium concentration remains elevated, so would the rate of spontaneous quantal release.

Several investigators have quantitatively examined facilitation and/or delayed release to see if they could be explained entirely in terms of residual calcium (Barrett and Stevens, 1972a, b; Magleby, 1973; Magleby and Zengel, 1973, 1975a, b, 1976ac; Zengel and Magleby, 1977, 1980, 1981, 1982). The major conclusion is that much of the data is explainable in terms of residual calcium, although certain discrepancies exist. For example, a model in which release was proportional to the fourth power of the internal $\mathrm{Ca}^{\text {2+ }}$ predicts that delayed release should decay more than 3-fold faster than facilitation. In actuality, the

\footnotetext{
Received Oct. 7, 1985; revised Jan. 27, 1986; accepted Feb. 17, 1986.

This work was supported by NINCDS Grant 10320 .

Correspondence should be addressed to Dr. William Van der Kloot at the above address.

Copyright (C) 1986 Society for Neuroscience $0270-6474 / 86 / 082366-05 \$ 02.00 / 0$
}

time courses for the decay of both were found to be quite similar, so it was concluded that the two, although casually related, could not be explained by a fourth-power residual calcium model (Zengel and Magleby, 1981).

One major difficulty in each of the earlier models is that they assumed a cooperativity of, at most, 4 for the action of $\mathrm{Ca}^{2+}$ in eliciting the release of a quantum of transmitter. This restriction was based on the results of Dodge and Rahamimoff (1967) relating external $\left[\mathrm{Ca}^{2+}\right]$ to evoked quantal output. More recently, Barton et al. (1983) reinterpreted these experiments, showing that the dependence of output on external $\left[\mathrm{Ca}^{2+}\right]$ implies that the number of calcium ions cooperating to cause release of a quantum of transmitter is at least 4 , with no upper limit defined. Given this reinterpretation, we reinvestigated the question of whether residual calcium could account for both facilitation and delayed release at the frog neuromuscular junction.

The present study tests the residual calcium hypothesis by comparing the magnitude and time course of facilitation and delayed release at the same neuromuscular junctions. Barton (1977) showed that if all spontaneous and evoked release rates are unique, nonsaturable, cooperative functions of the intracellular calcium concentration, then the ratio of delayed release to resting, spontaneous release should always be greater than facilitation. We have now extended the model to the more realistic case in which release is a saturable function of intracellular calcium concentration (Barton et al., 1983); again, the prediction is that delayed release should always be greater than facilitation. We tested this prediction at the frog neuromuscular junction. The results suggest that in this preparation the residual calcium hypothesis might explain the relation between facilitation and delayed release. However, there is an abrupt decline in the frequency of delayed release at a time when facilitation is almost unchanged, which is difficult to account for by residual calcium.

\section{Materials and Methods}

All experiments were performed on the sciatic nerve-sartorius muscle preparation from the frog, Rana pipiens. The frogs were stored in running water at $10^{\circ} \mathrm{C}$ until use. The dissection was performed in Ringer's containing (in $\mathrm{mM}$ ): $120 \mathrm{NaCl}, 2 \mathrm{KCl}, 2.5 \mathrm{CaCl}_{2}$, and $4 \mathrm{~N}$-tris (hydroxymethyl) methyl-2-aminoethanesulfonic acid (TES) at pH 7.4. Then, the preparations werc pinned on to the thin silicone rubber base of a Plexiglas bath, with a total volume of $5 \mathrm{ml}$. The bath was mounted on a Peltier plate, whose temperature could be regulated to $\pm 0.1^{\circ} \mathrm{C}$. A fine thermistor was placed next to the muscle in the bath to monitor the temperature continuously. The bath was filled with a solution containing (in $\mathrm{mm}$ ): $120 \mathrm{NaCl}, 10 \mathrm{MgCl}_{2}, 2 \mathrm{KCl}$, and 4 TES. When nerve stimulation produced no detectable contraction, the solution was replaced with one containing $0.2-1.2 \mathrm{mM} \mathrm{CaCl}_{2}$ or $\mathrm{SrCl}_{2}$, replacing the same amount of $\mathrm{MgCl}_{2}$. Recording was begun after the preparation was in the low $\mathrm{Ca}^{2+}-$ high $\mathrm{Mg}^{2+}$ solution for at least $15 \mathrm{~min}$. The electrodes and data collection methods were described by Van der Kloot and Cohen (1984b).

The next step was to record at least 100 miniature end-plate potentials (mepps) on an inkwriter. The record was used to calculate the mepp frequency. To measure facilitation, the nerve was stimulated by pairs of supramaximal stimuli ( $0.8 \mathrm{msec}$ in duration), separated by intervals 

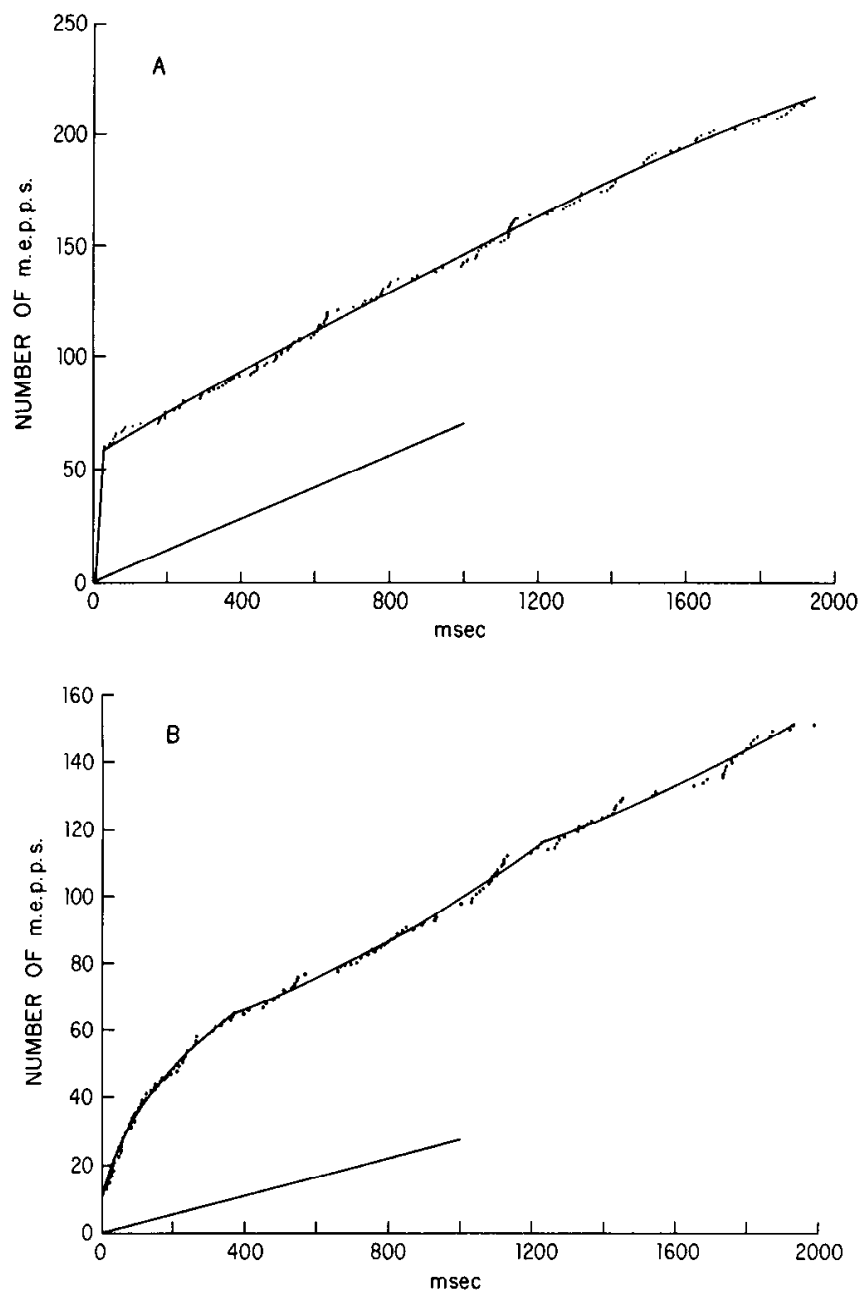

Figure 1. A, Data from a preparation in low $\mathrm{Ca}^{2+}-$ high $\mathrm{Mg}^{2+}$ solution at $8.3^{\circ} \mathrm{C}$. The points show the delayed release, expressed as the total number of mepps recorded as a function of the time following nerve stimulation; curves running close to the points were calculated from 2 third-degree polynomials fit to the data points; straight line beneath the points and curves shows the expected spontaneous mepp release in the unstimulated preparation. $B$, Data from a preparation in $\mathrm{Sr}^{2+}$ solution at $15^{\circ} \mathrm{C}$. The points, curves, and line are the same as in $A$, except that 3 polynomials were used to fit the points.

ranging from 10 to $500 \mathrm{msec}$. The pairs of shocks were delivered once every $5 \mathrm{sec}$. The mepp frequency was measurcd during the last sccond in the interval before the pair of stimuli; the results consistently showed that the frequency had returned to the background level. The portion of the records containing the end-plate potentials (epps) elicited by the stimuli were digitized at frequencies between 1000 and $12,500 \mathrm{~Hz}$, depending on the interval between the pairs of stimuli, and stored on a magnetic disk. Later, the records were used to measure the amplitudes and time integrals of the epps (see Van der Kloot and Cohen, 1984b). Each record was examined before the measurements were made to make certain that none of the traces was distorted by artifacts. The resting potential was continuously monitored during the measurements, so that the epps could be corrected for nonlinear summation to a standard potential of $-90 \mathrm{mV}$ (Katz and Thesleff, 1957; Van der Kloot and Cohen, 1984a). The epp data were used to calculate the mean responses to the first and second stimulus of the pair, their ratio was used to calculate the facilitation. In most experiments, the initial resting potential was above $-90 \mathrm{mV}$, and the experiment was terminated if the resting potential fell by more than $15 \mathrm{mV}$.

Following the facilitation measurements, the preparations were stimulated at $0.2 \mathrm{~Hz}$ with single stimuli. The electrical record was digitized at $1000 \mathrm{~Hz}$ for $2 \mathrm{sec}$ following each stimulus and the record stored on disk. The number of records obtained varied from 200 to 1000 , de- pending on the experiment. Later the records were displayed on a video screen and an operator positioned a cursor at the beginning of each mepp, recording the time elapsing from the peak of the epp to the beginning of each mepp. Control records were taken to make certain that the mepp frequency had fallen to the baseline level by the fourth second following the stimulus.

To calculate the rate of delayed release, all of the intervals between the peak of the epp and the beginning of each mepp from an experiment were sorted into ascending order. The data were then plotted as a cumulative distribution function, with the total number of intervals observed plotted as a function of the elapsed time (Fig. 1). As Figure $1 \mathrm{~A}$ illustrates, in $\mathrm{Ca}^{2+}$ solution delayed release following single stimuli occurs in 2 phases (Erulkar and Rahamimoff, 1978; Zengel and Magleby, 1981): a period of relatively rapid spontaneous release that, in $\mathrm{Ca}^{2+}$ solution at $8.3^{\circ} \mathrm{C}$, lasts for about $30 \mathrm{msec}$, followed by a second, slowly declining phase. The cumulative curve shows these phases as a relatively rapid initial rise followed by a transition to a lower slope. These 2 phases of delayed release have been fit by the sum of 2 exponentials (Zengel and Magleby, 1981). We chose to approximate the cumulative curve by using second-degree polynomials fit by least squares. Two or 3 polynomials were required; the points of transition between the polynomials were determined by trial and error. Two polynomials were used to fit the data shown in Figure $1 A$. Then, the polynomials were differentiated to give curves for the mepp frequency as a function of time following the stimulus. Finally, the rates were divided by the baseline mepp frequency, giving a curve for the delayed release. (We could have avoided the transitions between polynomials by fitting the entire cumulative curves with a cubic spline, but it was clear that this more involved procedure would add nothing to its analysis.)

Figure $1 B$ shows a cumulative curve for delayed release in $\mathrm{Sr}^{2+}$ solution. Again, there appear to be 2 phases, but the duration of both phases is markedly elongated compared to results in $\mathrm{Ca}^{2+r}$ solution. Three polynomials were used to fit the points in Figure $1 B$.

When evaluating the cumulative curves for delayed release, it is important to recognize the extent of the statistical error inherent in these measurements. For example, in Figure $1 A$ during the first rapid phase of release we recorded about 60 mepps. For a Poisson process, the SD is $(60)^{0.5}=7.75$, and the $95 \%$ confidence interval will be almost twice that. Therefore, we really are dealing with a range between about 45 and 75.

\section{Results}

\section{Theory}

The derivation presented below follows from the elaboration of the model of Dodge and Rahamimoff (1967) by Barton et al. (1983). The spontaneous release rate $(v)$ before a stimulus is given by

$$
v=k_{\max } b^{n} /\left(K_{m}+b\right)^{n}
$$

where $k_{\max }$ is the maximum output from the terminal, $b$ is the resting $\left[\mathrm{Ca}^{2+}\right]$ in the terminal, $K_{m}$ is the calcium concentration at which half the receptors are bound, and $n$ is the number of $\mathrm{Ca}^{2+}$ that cooperate to release a quantum of transmitter.

The evoked rate $(m)$ is given by

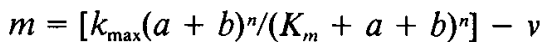

where $a$ is the increase in intracellular $\left[\mathrm{Ca}^{2+}\right]$ brought about by the stimulus.

Since $m \gg v$,

$$
m \cong k_{\max }(a+b)^{n} /\left(K_{m}+a+b\right)^{n}
$$

Following the stimulus, the $\left[\mathrm{Ca}^{2+}\right]$ increase declines with a time course $c(t)$.

Thus, during this period of delayed relcasc, the spontaneous rate is given by

$$
v_{2}=\frac{k_{\max }(b+c(t))^{n}}{\left(K_{m}+b+c(t)\right)^{n}}
$$

Similarly, if a second stimulus yields the same change in $\left[\mathrm{Ca}^{2+}\right]_{i}$ 


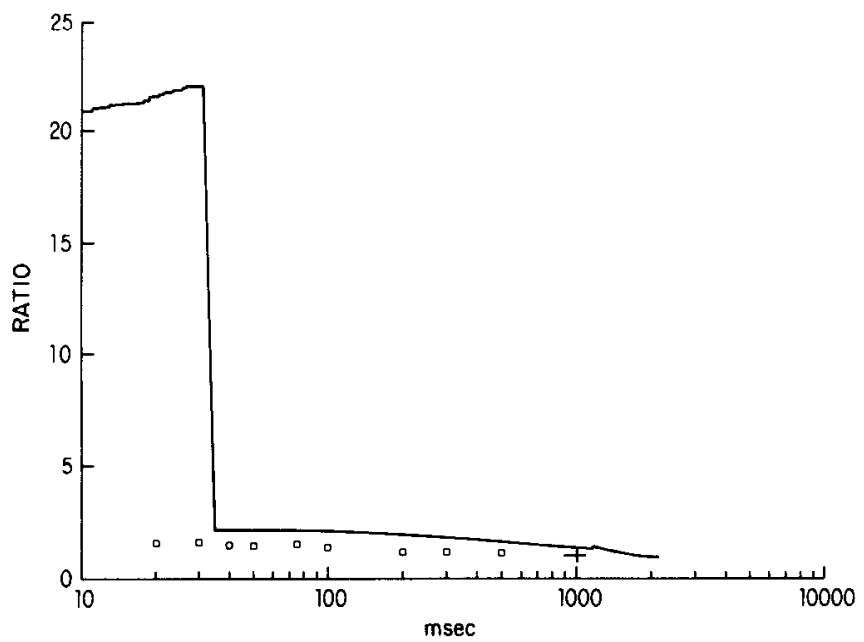

Figure 2. Results from an experiment in low $\mathrm{Ca}^{2+}$-high $\mathrm{Mg}^{2+}$ solution at $8.3^{\circ} \mathrm{C}$ (the same experiment illustrated in Fig. $1 \mathrm{~A}$ ). The solid curve shows the ratio of the mepp frequency to the resting, spontaneous frequency as a function of time following nerve stimulation, estimated by the method described in the text; points show facilitation in the same preparation as a function of the time interval between the pairs of stimuli; horizontal bar of the cross shows the resting mepp frequency (that is, a ratio of 1.0 ) \pm the $95 \%$ confidence limit. Note that at all time points, delayed release is greater than facilitation.

that the first stimulus caused, the facilitated evoked output is given by

$$
m_{2}=\frac{k_{\max }(a+b+c(t))^{n}}{\left(K_{m}+a+b+c(t)\right)^{n}}-v_{2}
$$

However, since $m_{2}>v_{2}$,

$$
m_{2} \cong \frac{k_{\max }(a+b+c(t))^{n}}{\left(K_{m}+a+b+c(t)\right)^{n}}
$$

Facilitation $(F)$ is defined as $m_{2} / m$, while the ratio of delayed release to resting, spontaneous release $(D)$ is defined as $v_{2} / v$.

It is possible to demonstrate by a series of algebraic manipulations that if the above equations describe the relationship between facilitation and delayed release, that

$$
D(t) \geq F(t)
$$

for all $t$. The details of this derivation are in Cohen and Van der Kloot (1985). This prediction of the residual calcium modelthat $D$ must always be greater than $F$-is the rationale for the experiments presented next.

\section{Comparing facilitation and delayed release}

Figure 2 shows the results of an experiment in low $\mathrm{Ca}-\mathrm{high} \mathrm{Mg}$ Ringer's at $8.3^{\circ} \mathrm{C}$. The solid line shows delayed release (calculated from the polynomials fitting the points in Fig. $1 A$ ), which was sustained at a high level for roughly $20 \mathrm{msec}$ following the stimulus and then abruptly fell to a level slightly higher than the resting rate. The curve shows that delayed release increases somewhat during the first $20 \mathrm{msec}$ following stimulation. Similar apparent increases were seen in 3 of 8 experiments in $\mathrm{Ca}^{2+}$ solution. It is by no means certain that this rise is real. We have already pointed out the statistical variability inherent in the experiment. We are also concerned because the most difficult mepps to distinguish are those on the falling phase of the epp. If some of these are missed and are therefore not included in the cumulative curve, there might be an artifactual, initial upward slope. On the other hand, in some experiments facilitation also rises with increasing time between the stimulus pairs, reach-

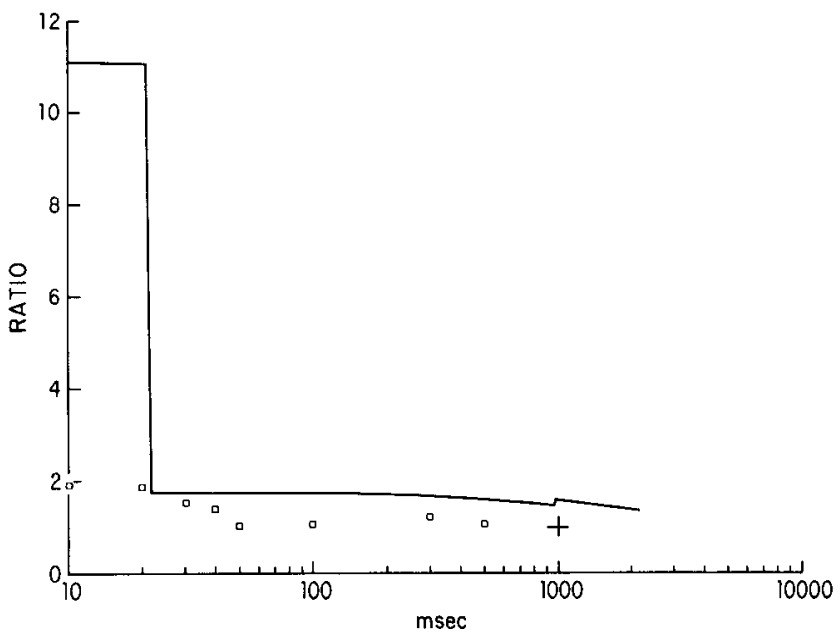

Figure 3. Results of an experiment in low $\mathrm{Ca}^{2+}$-high $\mathrm{Mg}^{2+}$ solution at $15^{\circ} \mathrm{C}$. The curve, points, and cross are as described in the legend to Figure 2. Note that at all time points, delayed release is greater than facilitation.

ing a maximum at about 20 msec. We can make no firm conclusion as to whether the rate of delayed release sometimes increased during the initial interval following the stimulus.

Again referring to Figure 2, facilitation was always less than delayed release. At $20 \mathrm{msec}$, the first point measured, facilitation was 1.6 and delayed release was about 22 . At $40 \mathrm{msec}$, delayed release had fallen to about 2 , while facilitation was still at 1.6. This behavior, in which delayed release falls much more rapidly than facilitation, was found in all of our preparations in $\mathrm{Ca}^{2+}$ solution.

Figure 3 summarizes an experiment in low $\mathrm{Ca}^{2+}$-high $\mathrm{Mg}^{2+}$ at $15^{\circ} \mathrm{C}$. The same generalizations stand out: At $10 \mathrm{msec}$, delayed release is about 11 and facilitation is 1.9 , while at $30 \mathrm{msec}$, delayed release is 1.9 and facilitation is 1.5.

Figure 4 shows the results from an experiment in $\mathrm{Sr}^{2+}$-containing solution at $15^{\circ} \mathrm{C}$. Delayed release was sustained for a longer time, and there was less an obvious division into 2 phases. Delayed release was always substantially greater than facilitation.

Table 1 summarizes the data from all of the experiments. Two points are given for each experiment. For the experiments

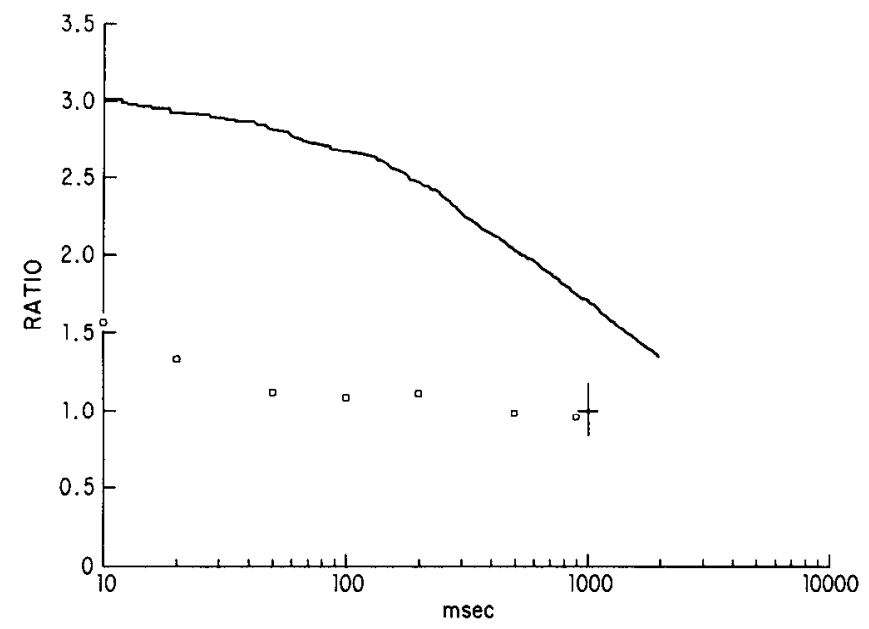

Figure 4. Results of an experiment in $\mathrm{Sr}^{2+}$ solution at $15^{\circ} \mathrm{C}$. The curve, points, and cross are all as described in the legend to Figure 2 . Note that at all time points, delayed release is greater than facilitation. 


\begin{tabular}{|c|c|c|c|c|}
\hline Exp. no. & $\begin{array}{l}\text { Temp. } \\
\left({ }^{\circ} \mathrm{C}\right)\end{array}$ & $\begin{array}{l}\text { Time } \\
(\mathrm{msec})\end{array}$ & Facilitation & $\begin{array}{l}\text { Delayed } \\
\text { release }\end{array}$ \\
\hline \multicolumn{5}{|c|}{$\mathrm{Ca}^{2+}$ solution } \\
\hline \multirow[t]{2}{*}{ I } & 8.3 & 30 & 1.6 & 23.0 \\
\hline & & 40 & 1.5 & 2.2 \\
\hline \multirow[t]{2}{*}{ II } & 8.3 & 40 & 1.5 & 27.1 \\
\hline & & 50 & 1.4 & 1.3 \\
\hline \multirow[t]{2}{*}{ III } & 8.3 & 30 & 1.6 & 36.0 \\
\hline & & 40 & 1.6 & 1.4 \\
\hline \multirow[t]{2}{*}{ IV } & 15.0 & 20 & 1.9 & 11.0 \\
\hline & & 30 & 1.5 & 2.0 \\
\hline \multirow[t]{2}{*}{ V } & 15.0 & 30 & 1.4 & 4.8 \\
\hline & & 40 & 1.4 & 1.9 \\
\hline \multirow[t]{2}{*}{ VI } & 15.0 & 15 & 1.5 & 10.0 \\
\hline & & 30 & 1.4 & 6.0 \\
\hline \multicolumn{5}{|c|}{$\mathrm{Sr}^{2+}$ solution } \\
\hline \multirow[t]{2}{*}{ VII } & 15.0 & 10 & 1.6 & 3.0 \\
\hline & & 500 & 1.0 & 2.0 \\
\hline \multirow[t]{2}{*}{ VIII } & 15.0 & 10 & 1.7 & 1.7 \\
\hline & & 200 & 1.0 & 1.5 \\
\hline \multirow[t]{2}{*}{ IX } & 15.0 & 50 & 1.3 & 2.6 \\
\hline & & 900 & 0.9 & 1.6 \\
\hline \multirow[t]{2}{*}{$\mathrm{X}$} & 12.0 & 100 & 1.5 & 5.7 \\
\hline & & 980 & 1.0 & 2.6 \\
\hline \multirow[t]{2}{*}{ XI } & 12.0 & 20 & 2.3 & 6.4 \\
\hline & & 500 & 0.9 & 4.3 \\
\hline \multirow[t]{2}{*}{ XII } & 12.0 & 10 & 1.7 & 1.6 \\
\hline & & 500 & 1.0 & 2.8 \\
\hline \multirow[t]{2}{*}{ XIII } & 18.0 & 10 & 1.7 & 2.0 \\
\hline & & 200 & 1.0 & 1.9 \\
\hline
\end{tabular}

in $\mathrm{Ca}^{2+}$ solution, we chose the 2 points on either side of the sharp decline in the rate of delayed release. The summary shows how sharply delayed release fell, whereas there was little change in facilitation. The data in $\mathrm{Sr}^{2+}$ solution show the time of maximum facilitation and the data when facilitation had first reached 1.0 , or close to 1.0 , showing that the rate of delayed release could still be substantially elevated.

Three other points are shown by the data. (1) The rates of delayed release were substantially less in $\mathrm{Sr}^{2+}$ solution than in $\mathrm{Ca}^{2+}$ solution. (2) Facilitation was about the same in $\mathrm{Sr}^{2+}$ solution and in $\mathrm{Ca}^{2+}$ solution. (3) Delayed release was enhanced at lower temperatures.

\section{Discussion}

The principal experimental problem was the measurement of delayed release. The number of extra quanta spontaneously released following a stimulus is usually small and is superimposed on the resting rate of release. This inevitably contributes substantial scatter to the data.

Zengel and Magleby (1981) studied the decay of mepp frequencies following trains of 200 stimuli delivered at $20 / \mathrm{sec}$. They measured the time of appearance of 47,295 mepps and concluded that the initial 2 phases of decay, over the time periods discussed in this paper, could be fit by exponentials with time constants of about 47 and $472 \mathrm{msec}$.

We undertook the experiments to determine whether the ratio of delayed release to resting, spontaneous release was always greater than facilitation, in agreement with the predictions of a model in which both depend on residual $\mathrm{Ca}^{2+}$. Facilitation and delayed release were measured at the same junctions. In our experiments in both $\mathrm{Ca}^{2+}$ and $\mathrm{Sr}^{2+}$ solutions at 2 temperatures, the ratio of delayed release to resting, spontaneous release was indeed always greater than facilitation.

One possible complication in our calculation is worth considering. A Ca ${ }^{2+}$-independent fraction of spontaneous release exists (Hubbard et al., 1968; Quastel et al., 1971). If this contribution to the spontaneous release rate is subtracted from both $v$ (the resting spontaneous rate) and $v_{2}$ (the spontaneous rate following a stimulus), then since $v_{2}>v$, the ratio $v_{2} / v$ is increased. This will not reverse but, instead, improve the agreement with the predictions of a residual calcium hypothesis.

On the other hand, despite our inability to reject the hypothesis that residual calcium accounts for facilitation and delayed release, a number of observations remain puzzling. These include the facts that (1) the abrupt reduction in delayed release following a stimulus in $\mathrm{Ca}^{2+}$ solution is unaccompanied by a similarly abrupt drop in the amplitude of the facilitated epp and (2) that facilitation in $\mathrm{Sr}^{2+}$ solution terminates well before delayed release. These 2 additional observations suggest that if both facilitation and delayed release are caused by residual calcium, the functional relationship between $\left[\mathrm{Ca}^{2+}\right]$ and quantal output must be complex.

\section{References}

Baldo, G. J., I. S. Cohen, and W. Van der Klool (1983) Facilitation and the conduction of nerve action potential at the frog neuromuscular junction. Pfluegers Arch. 399: 161-165.

Barrett, E. F., and C. Stevens (1972a) Quantal independence and uniformity of presynaptic release kinetics at the frog neuromuscular junction. J. Physiol. (Lond.) 227: 665-689.

Barrett, E. F., and C. Stevens (1972b) The kinetics of transmitter release at the frog neuromuscular junction. J. Physiol. (Lond.) 227: 691-708.

Barton, S. B. (1977) Facilitation and delayed release of transmitter at the frog neuromuscular junction. D. Phil. thesis, University of Oxford.

Barton, S. B., and I. S. Cohen (1982) Facilitation and impulse propagation failure at the frog neuromuscular junction. Pfluegers Arch. 392: 327-334.

Barton, S. B., I. S. Cohen, and W. Van der Kloot (1983) The calcium dependence of spontaneous and evoked release at the frog neuromuscular junction. J. Physiol. (Lond.) 337: 735-752.

Charlton, M. P., and G. D. Bittner (1978) Facilitation of transmitter release at squid synapses. J. Gen. Physiol. 72: 471-486.

Cohen, I. S., and W. Van der Kloot (1985) Calcium and transmitter release. Int. Rev. Neurobiol. 27: 299-336.

Del Castillo, J., and B. Katz (1954) Statistical factors involved in neuromuscular facilitation and depression. J. Physiol. (Lond.) 124: 574-585.

Dodge, F. A., and R. Rahamimoff (1967) Co-operative action of calcium ions in transmitter release at the neuromuscular junction. $J$. Physiol. (Lond.) 193: 419-432.

Erulkar, S. D., and R. Rahamimoff (1978) The role of calcium ions in tctanic and post-tetanic increase of miniature end-plate potential frequency. J. Physiol. (Lond.) 278: 501-511.

Hoshi, T., J. Rothlein, and S. J. Smith (1984) Facilitation of $\mathrm{Ca}^{2+}$ channel currents in bovine adrenal chromaffin cells. Proc. Natl. Acad. Sci. USA 81: 5871-5875.

Hubbard, J. I., S. F. Jones, and E. M. Landau (1968) An examination of the effects of osmotic pressure changes on the spontaneous activity of nerve terminals. J. Physiol. (Lond.) 197: 689-697.

Hurlbut, W. P., H. B. Longenecker, Jr., and A. Mauro (1971) Effects of calcium and magnesium on the frequency of miniature end-plate potentials during prolonged tetanization. J. Physiol. (Lond.) 219:1738.

Katz, B., and R. Miledi (1968) The role of calcium in neuromuscular facilitation. J. Physiol. (Lond.) 195: 481-492.

Katz, B., and S. Thesleff (1957) On the factors which determine the amplitude of the "miniature end-plate potential." J. Physiol. (Lond.) 138: $267-278$.

Liley, A. W. (1956) An investigation of spontaneous activity at the neuromuscular junction of the rat. J. Physiol. (Lond.) 132: 650-666. 
Lloyd, D. C. P. (1949) Post-tetanic potentiation of response in monosynaptic reflex pathways of the spinal cord. J. Gen. Physiol. 33: 147170.

Magleby, K. L. (1973) The effects of repetitive stimulation on facilitation of transmitter release at the frog neuromuscular junction. J. Physiol. (Lond.) 234: 327-352.

Magleby, K. L., and J. E. Zengel (1973) The effects of tetanic and posttetanic potentiation on facilitation of transmitter release at the frog neuromuscular junction. J. Physiol. (Lond.) 234: 353-371.

Magleby, K. L., and J. E. Zengel (1975a) A dual effect of repetitive stimulation on post-tetanic potentiation of transmitter release at the frog neuromuscular junction. J. Physiol. (Lond.) 245: 163-182.

Magleby, K. L., and J. E. Zengel (1975b) A quantitative description of tetanic and post-tetanic potentiation of transmitter release at the frog neuromuscular junction. J. Physiol. (Lond.) 245: 183-208.

Magleby, K. L., and J. E. Zengel (1976a) Augmentation: A process that acts to increase transmitter release at the frog neuromuscular junction. J. Physiol. (Lond.) 257: 449-470.

Magleby, K. L., and J. E. Zengel (1976b) Long-term changes in augmentation, potentiation, and depression of transmitter release as a function of repeated synaptic activity at the frog neuromuscular junction. J. Physiol. (Lond.) 257: 471-494.

Magleby, K. L., and J. E. Zengel (1976c) Stimulation-induced factors which affect augmentation and potentiation of transmitter release at the frog neuromuscular junction. J. Physiol. (Lond.) 260: 687-717.

Mallart, A., and A. R. Martin (1967) An analysis of the facilitation of transmitter release at the neuromuscular junction of the frog. $J$. Physiol. (Lond.) 193: 679-694.

Miledi, R., and R. Thies (1971) Tetanic and post-tetanic rise in fre- quency of miniature end-plate potentials in low-calcium solutions. J. Physiol. (Lond.) 212: 245-257.

Quastel, D. M. J., J. T. Hackett, and J. D. Cooke (1971) Calcium: Is it required for transmitter secretion? Science New York 172: 10341036.

Rahamimoff, R., and Y. Yaari (1973) Delayed release of transmitter at the frog neuromuscular junction. J. Physiol. (Lond.) 228: 241-257.

Stinnakre, J., and L. Tauc (1973) Calcium influx in active Aplysia neurons. Nature 242: 113-115.

Van der Kloot, W., and I. S. Cohen (1984a) End-plate potentials in a model muscle fiber: Corrections for the effects of membrane potential on currents and channel lifetimes. Biophys. J. 45: 905-912.

Van der Kloot, W., and I. S. Cohen (1984b) Temperature effects on spontaneous and evoked quantal size at the frog neuromuscular junction. J. Neurosci. 4: 2200-2203.

Zengel, J. E., and K. L. Magleby (1977) Transmitter release during repetitive stimulation: Selective changes produced by $\mathrm{Sr}^{2+}$ and $\mathrm{Ba}^{2+}$. Science 197: 67-69.

Zengel, J. E., and K. L. Magleby (1980) Differential effects of $\mathrm{Ba}^{2+}$, $\mathrm{Sr}^{2+}$, and $\mathrm{Ca}^{2+}$ on stimulation-induced changes in transmitter release at the frog neuromuscular junction. J. Gen. Physiol. 76: 175-211.

Zengel, J. E., and K. L. Magleby (1981) Changes in miniature endplate potential frequency during repetitive nerve stimulation in the presence of $\mathrm{Ca}^{2+}, \mathrm{Ba}^{2+}$, and $\mathrm{Sr}^{2+}$ at the frog neuromuscular junction. J. Gen. Physiol. 77: 503-529.

Zengel, J. E., and K. L. Magleby (1982) Augmentation and facilitation of transmitter release: A quantitative description at the frog neuromuscular junction. J. Gen. Physiol. 80: 583-611. 